\section{EMBRYRIDDLE \\ Aeronautical University}

SCHOLARLY COMMONS
International Journal of Aviation, Aeronautics, and Aerospace

\title{
Difference in attitudes toward Crew Resource Management based on nationality
}

\author{
Christoph Zurman \\ Embry-Riddle Aeronautical University, c_zurman@web.de \\ Herbert O. Hoffmann \\ Embry-Riddle Aeronautical University, hoffm7d5@erau.edu \\ Hans-Joachim K. Ruff-Stahl \\ Embry-Riddle Aeronautical University, ruffha@erau.edu
}

Follow this and additional works at: https://commons.erau.edu/ijaaa

Part of the Human Factors Psychology Commons, and the Multicultural Psychology Commons

\section{Scholarly Commons Citation}

Zurman, C., Hoffmann, H. O., \& Ruff-Stahl, H. K. (2019). Difference in attitudes toward Crew Resource Management based on nationality. International Journal of Aviation, Aeronautics, and Aerospace, 6(4). https://doi.org/10.15394/ijaaa.2019.1331

This Article is brought to you for free and open access by the Journals at Scholarly Commons. It has been accepted for inclusion in International Journal of Aviation, Aeronautics, and Aerospace by an authorized administrator of Scholarly Commons. For more information, please contact commons@erau.edu. 
Crew Resource Management (CRM) not only shapes the multi-crew concept in aviation but it is an important core component of this entire professional culture. CRM may range from "soft" ideas, such as teambuilding prior to commencing a flight, or "hard" actions, such as emergency handling procedures (Kanki, Helmreich \& Anca, 2010). In order for CRM to function, it is important that all members of a team share a positive and open attitude toward its principles (Gordon, Mendenhall, \& O'Connor, 2012; Kanki et al., 2010). Yet, national culture might interfere with professional culture at this point (Kanki et al., 2010). Hence, this research project seeks to identify whether nationality has a significant effect on a crew member's attitude toward CRM.

In general, the purpose of CRM is to enhance safety within the air transportation system by arguing that CRM makes crews less susceptible to fatal outcomes after a single error has occurred. In the early 1980s, CRM was designed to overcome the single-pilot mindsets of many captains who have flown singleseat fighter aircraft previously (Gordon et al., 2012). Once subordinate crewmembers noticed a discrepancy or unsafe act, this group of single-seat fighter pilots would not accept their views, let alone interventions. Yet airlines, which have expanded to global companies including ten thousand employed aircrew members, needed to change. Subsequently, compressed schedules made crews fly together for only several legs, in some cases only a single leg. Adapting to the behavioral particularities of each pilot or accepting the single-pilot mentality of some was not a viable option anymore (Gordon et al., 2012). Even though several studies over the last two decades questioned the overall effectiveness of CRM, most of the peer reviewed scientific studies show a positive impact on leadership, crew forming, and communication (Besco, 1997; Komich, 1997; Salas, Wilson \& Burke, 2006; Simmon, 1997).

To increase CRMs effectiveness and to find out which preconditions affect CRM, the mechanics and factors that influence it positively and negatively have to be studied independently. Several such studies focus on the different attitudes that crews may have toward CRM, based on their personality (Aktas \& Tekarslan, 2013). These different personalities could be linked to professional and occupational origins such as; age, educational status, origin, aircraft types, or flight experience (Aktas \& Tekarslan, 2013). However, not linked were the different attitudes toward CRM, and the nationalities or national cultures of crewmembers (Aktas \& Tekarslan, 2013). Yet, as Hofstede's (2001) cultural dimensions theory suggested, a person's national culture and roots will result in significant differences within various aspects of the human psyche. Founded on his pioneering and fundamental research data, other researchers previously linked these findings to flight crews and their CRM performance (Helmreich, Wilhelm, Klinect \& Merritt, 2001; Helmreich \& Merritt, 2016; Merritt \& Helmreich, 1996). 
In contrast, airline operations in the last decade have become increasingly multinational, and airlines routinely assign random aircrews for each flight. Furthermore, airline crews are recruited globally to balance the demand for pilots and flight attendants augmenting the local supply of personnel, e.g. in Asia (Reid, 2017). Similarly, military operations have gradually evolved into more globalized combined operations; henceforth several nations' forces are working together in one operational scenario. The NATO E-3A Component is a representative for such conditions: Established in the early 1980s, it is the first standing multinational -military NATO unit that currently employs aircrew members from 15 of the 28 NATO nations ("E-3A Component", 2018; "Participating Nations", 2018). Consequently, the question presents itself, whether this introduces a new set of problems in terms of different national cultures. As Hofstede's theory of cultural dimensions specifically suggests, nationalities have vastly different attitudes toward concepts such as trans-cockpit authority (authority gradients in the cockpit between the captain / commander and other crew members), individuality, or restraint (Hofstede, 2001), which in turn may call new and adapted CRM concepts.

Subsequently, the purpose of this study is to reveal, based primarily on the crew-member's nationality, whether there are different attitudes toward CRM. Furthermore, additional information, such as gender, age, position within the crew, time in the company, age, or school education will be used in order to evaluate if certain discrepancies can be recognized based on secondary or extraneous factors.

If such differences in fact do exist, the question presents itself, whether these differences can be linked to any regularity. For this, a specially designed questionnaire collects data necessary to calculate cultural dimension indices according to Hofstede (2001). It is hoped that this will help determine whether certain index patterns are more prone to indicate a negative attitude toward CRM, and what measures, trainings, or procedures may improve the attitude toward $\mathrm{CRM}$ in the future.

Specifically, the following research questions were addressed: First, does a NATO E-3A aircrew-member's nationality influence his or her attitude toward CRM? Second, do other personal factors; such as gender, crew position, time spent in the NATO E-3A Component, age, or school education of NATO E-3A aircrew-members; influence his or her attitude toward CRM?

From these questions, the following hypotheses were chosen: First, there is a statistically significant difference in the attitude of NATO E-3A aircrewmembers toward CRM, based on their nationality, and second, there is a statistically significant difference in the attitude of NATO E-3A aircrew-members toward CRM, based on secondary factors such as gender, crew position, time spent in the NATO E-3A Component, age, or school education. 
These hypotheses were subdivided into the following six specific, testable null-hypotheses, using a $\mathrm{p}$-value of $\mathrm{p} \leq 0.05$ to measure significance:

H01: There is no statistically significant difference in the attitude of NATO E-3A aircrew-members toward CRM, based on their nationality. $\mathrm{H} 02$ : There is no statistically significant difference in the attitude of NATO E-3A aircrew-members toward CRM, based on their gender. H03: There is no statistically significant difference in the attitude of NATO E-3A aircrew-members toward CRM, based on their crew position. H04: There is no statistically significant difference in the attitude of NATO E-3A aircrew-members toward CRM, based on their time spent in the NATO E-3A Component. H05: There is no statistically significant difference in the attitude of NATO E-3A aircrew-members toward CRM, based on their age. H06: There is no statistically significant difference in the attitude of NATO E-3A aircrew-members toward CRM, based on their school education. Some limitations should be addressed up front. Firstly, and despite the large effects national diversities may have on the crew concept during various situations, this project will only examine the correlation between national culture and attitude toward CRM. Secondly, this research project will exclusively focus on a multinational NATO Air Force unit that operates large multi-crew E-3A aircraft under military rules. More importantly for the question, whether the results of this study can be generalized, the standard operating procedures are similar to any civil airline. It is therefore anticipated that the results of this research project will be somewhat transferrable to other multinational military and airline operations. Finally, all possible participants, are drawn from a comparable, westerly oriented cultural background. Even though discrepancies and differences between the various nationalities in general exist without any doubt, the participating NATO nationalities are comparable in regards to their history, selfimage, and self-perception as compared to Asian, South-American, or African cultures (Hofstede, 2001).

\section{Method}

A questionnaire, as shown in Appendix A, was prepared and distributed personally to all available crew members of the NATO E-3A Component and made available online via Google Forms. Primary data gained through that questionnaire were analyzed through a quantitative approach with a one-way analysis of variance (ANOVA). The questions were designed around a five-level Likert-type scale and mainly based on Hofstede and Minkov's (2013) Values Survey Module (VSM), adapted grammatically and in content only. This allowed the assessment of the six cultural dimension indices of Power Distance (PDI), Individualism (IDV), Masculinity (MAS), Uncertainty Avoidance (UAI), Long 
Term Orientation (LTO), and Indulgence versus Restraint (IVR). According to Hofstede (2001), these values are required to evaluate the sample's national groups' alignment with their national average, as well as to determine if national attitude differences toward CRM, if existing, could be linked to certain index patterns. Likewise, questions 30 to 36 were derived from the VSM as well, allowing the collection of demographic data such as age, education, crew position, and the independent variable, the individual's nationality. In addition, further questions were formulated to collect data about the individual's attitude directly toward CRM, yet without revealing the goal of the survey. Additionally, questions 27 and 29 were supplemented from Helmreich and Merritt's (2016) Flight Management Attitudes Questionnaire (FMAQ), a tool that was developed based on early versions of Hofstede and Minkov's VSM and precisely targeted for flight crews. Therefore, if these questions prove to provide enough data, a link between attitude toward CRM and certain index patterns based on Hofstede's (2001) six dimensions might be possible.

As the official working language within the NATO E-3A Component is English and a successful language test is a prerequisite to work in the Component, the baseline questions of the VSM could directly be used without the need for any translation. This was also applicable for the additional questions concerning the attitude toward CRM.

In total, about 1,400 people from 15 different nations are currently employed in the NATO E-3A Component, which provides a large potential sample size, because about a third of them are employed as air crew personnel within a CRM environment ("E3-A Component", 2018). The actual sample size consisted of 128 replies, of which 10 were incomplete and had to be discarded. A relatively small sample such as this one must be evaluated cautiously, when using this method (Eringa, Caudron, Rieck, Xie, \& Gerhart, 2015; Hofstede, 2001; Hofstede \& Minkov, 2013). Specifically, the procedure itself, the questions, and the surveying of the data are valid; however, the results for small samples must be analyzed with care: Hence, and to avoid extremely small groups, only country groups with four or more replies were used.

To base the results on solid and reliable foundations, different inferential statistical were used. The one-way ANOVA used in this study assumes a normal distribution of the variable within the study population. Hence to add robustness in conjunction with the disparate group sizes, a nonparametric Kruskal-Wallis Test was used when the normality of the population was in question (Keppel \& Wickens, 2004; Weiss, 2011).

From the raw data returned with the survey questionnaires, the cultural dimension indices were calculated based on the formulas of Hofstede and Minkov's Values Survey Model (VSM, 2013). With the results of the supplementary questions about participants' attitude toward CRM, a one-way 
ANOVA was performed to see if statistically significant differences were observed between the different nationality groups. Because not all questionnaires were complete, replies with lacking information were sorted out and not considered in the primary research question. Nevertheless, if information was existent in the particular columns, these incomplete questionnaires were still used as part of the calculation of secondary factors that are not related to peoples' nationalities.

Since the main goal of this study was to see if there are differences for the attitude toward CRM between crew members from different nations, the aforementioned added questions to assess this attitude were averaged per nation and group. A one-way ANOVA was then performed on the values to measure if the hypothesis can be supported or had to be rejected.

The one-way ANOVA was used to compare up to 11 different groups, which required a post hoc test in the form of a Tukey-HSD (Honest Significance Difference) to detect those groups that showed statistically significant differences.

As some groups were rather small, nations with less than five replies were discarded prior to the evaluation. As previously mentioned, the normal distribution of the variable within the study population could not always be assured but only assumed. Therefore, in addition to the one-way ANOVA, a Kruskal-Wallis test was performed for the primary independent variable, nationality.

\section{Results and Discussion}

A total of 128 questionnaires were accumulated over the 10-week period of the survey. Of these responses 61 were hard-copy questionnaires, while the other 67 were online versions filled out via the Google Forms platform. Of these 128 replies, 10 were incomplete with one or more answers missing. To ensure uniform treatment of the data, datasets containing improper answers were excluded from further calculations. As expected, most replies came from participants from Germany and the United States, as these countries make up for the largest part of the sample population in the NATO E-3A Component. Figure 1 illustrates the distribution of valid replies sorted by nationality.

The dashed line at " 4 " in the following figure indicates that nationalities with less than 5 valid replies were removed from the assessment of findings based on nationality. Averaging less than 5 results would increase the effects of outliners and decrease the reliability of the data. 


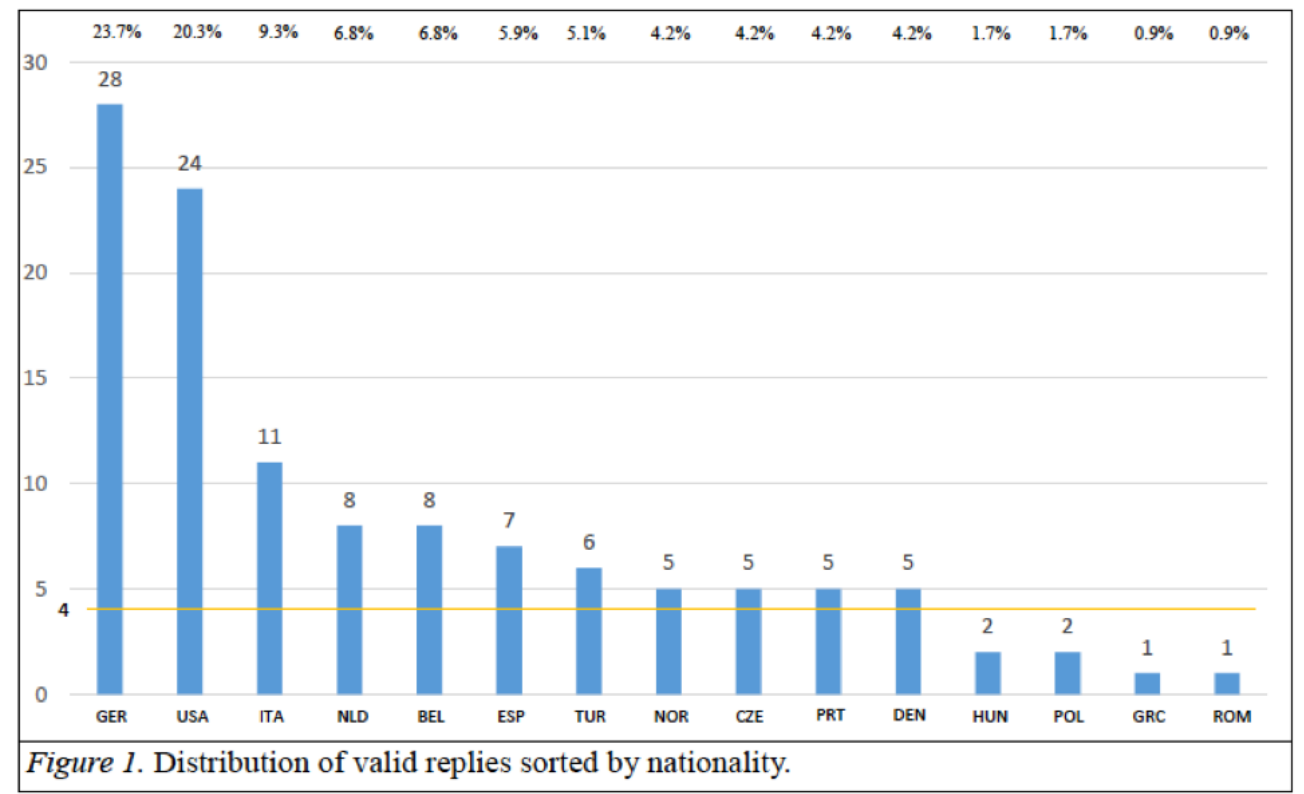

The primary scope of this research was the question if the nationality of NATO E-3A crew-members has an impact on their attitude toward CRM. The five supplemented questions of the survey were analyzed to assess if the hypothesized difference could be detected. Figure 2 displays a graphical depiction of the averaged answers to the five questions, sorted by countries with five or more valid questionnaire results. Some nation's averages vary greatly, especially for question 4 and 29.

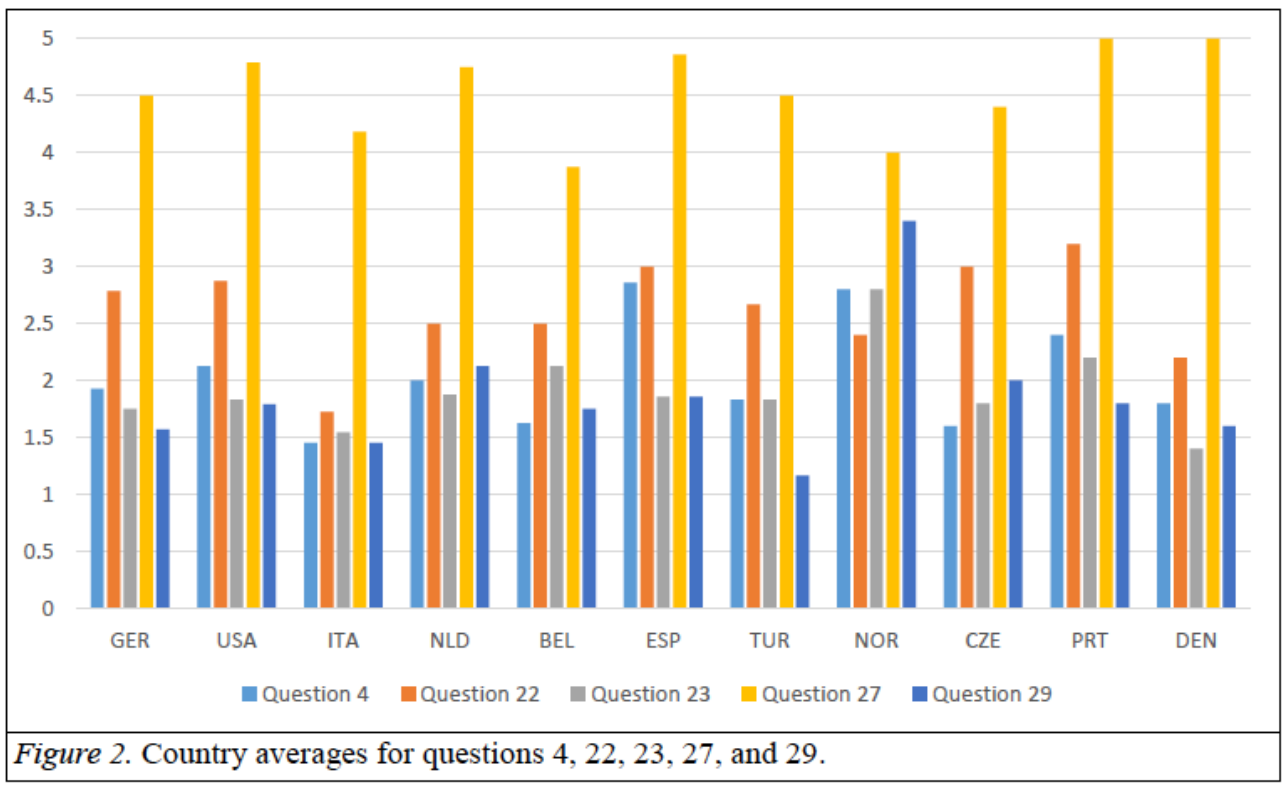


To determine if these dissimilarities are of statistical significance, a oneway ANOVA was performed with the results presented in table 1. Highlighted in green, p-values of 0.0092 and 0.0025 for questions 4 and 29 suggest that the averages are significantly different. Furthermore, a p-value of 0.0398 for question 27 indicates that the results are significantly different. Due to different group sizes and the possibility of having drawn a sample from a non-normal distributed population a Kruskal-Wallis test was run following the one-way ANOVA. The results are also shown in Table 1, and indicate the same outcome as the one-way ANOVA results.

Table 1

One-way ANOVA summary for questions 4, 22, 23, 27, 29 by countries.

\begin{tabular}{lcccccc}
\hline & & \multicolumn{5}{c}{ Mean } \\
\cline { 3 - 7 } & & Q-4 & Q-22 & Q-23 & Q-27 & Q-29 \\
\hline Germany & 28 & 1.93 & 2.79 & 1.75 & 4.50 & 1.57 \\
United States & 24 & 2.13 & 2.88 & 1.83 & 4.80 & 1.79 \\
Italy & 11 & 1.45 & 1.73 & 1.55 & 4.18 & 1.45 \\
Netherlands & 8 & 2.00 & 2.50 & 1.88 & 4.75 & 2.13 \\
Belgium & 8 & 1.63 & 2.50 & 2.13 & 3.88 & 1.75 \\
Spain & 7 & 2.86 & 3.00 & 1.86 & 4.86 & 1.86 \\
Turkey & 6 & 1.83 & 2.67 & 1.83 & 4.50 & 1.17 \\
Norway & 5 & 2.80 & 2.40 & 2.80 & 4.00 & 3.40 \\
Czech Republic & 5 & 1.60 & 3.00 & 1.80 & 4.40 & 2.00 \\
Portugal & 5 & 2.40 & 3.20 & 2.20 & 5.00 & 1.80 \\
Denmark & 5 & 1.80 & 2.20 & 1.40 & 5.00 & 1.60 \\
p-value & & 0.0092 & 0.0995 & 0.111 & 0.0398 & 0.0025 \\
(ANOVA) & & & & 9 & & \\
p-value & & & & & \\
(Kruskal- & & 0.0165 & 0.1144 & 0.385 & 0.0222 & 0.0198 \\
Wallis) & & & 6 & & \\
\hline
\end{tabular}

With the large number of groups used in this analysis, it was necessary to perform a Tukey HSD post hoc test for each question, where the ANOVA derived p-value implied a statistically significant difference. The results for question 4 are displayed in Table 2. With the regular ranking by number of replies, it became apparent that the only country discrepancies arose with Spain. Therefore, in this table, Spain was used as the leading factor from which the other values were subtracted. The results show that dissimilarities to trigger a $p$-value of $p \leq 0.05$ only exist between Spain and Italy. Overall, the difference between the group 
means is 1.4 , with a mean of 1.45 for Italy, and a mean of 2.86 for Spain. This is almost twice as high, when compared to the question regarding the personal perception of the importance of team work and communication training on a new job. The Italian survey participants describe it rather as "of utmost importance," while the Spanish ones only as "of moderate importance".

Table 2

Tukey HSD post hoc test results for question 4. (ANOVA p-value 0.0092)

\begin{tabular}{lcccc}
\hline Spain subtracted from & Difference & Lower & Upper & p-value \\
\hline Germany & -0.93 & -2.01 & 0.15 & 0.1610 \\
United States & -0.73 & -1.83 & 0.37 & 0.5122 \\
Italy & -1.40 & -2.64 & -0.17 & 0.0130 \\
Netherlands & -0.86 & -2.18 & 0.47 & 0.5556 \\
Belgium & -1.23 & -2.55 & 0.09 & 0.0912 \\
Turkey & -1.02 & -2.45 & 0.40 & 0.3948 \\
Norway & -0.06 & -1.55 & 1.44 & 1.000 \\
Czech Republic & -1.26 & -2.75 & 0.24 & 0.1860 \\
Portugal & -0.46 & -1.95 & 1.04 & 0.9951 \\
Denmark & -1.06 & -2.55 & 0.44 & 0.4239 \\
\hline
\end{tabular}

Table 3 shows the Tukey HSD post hoc test results for question 27.

Table 3

Tukey HSD post hoc test results for question 27. (ANOVA p-value 0.0398)

\begin{tabular}{lcccc}
\hline $\begin{array}{l}\text { Germany subtracted } \\
\text { from }\end{array}$ & Difference & Lower & Upper & p-value \\
\hline United States & 0.29 & -0.39 & 0.98 & 0.9453 \\
Italy & -0.32 & -1.20 & 0.56 & 0.9817 \\
Netherlands & 0.25 & -0.74 & 1.24 & 0.9990 \\
Belgium & -0.63 & -1.61 & 0.36 & 0.5913 \\
Spain & 0.36 & -0.68 & 1.40 & 0.9879 \\
Turkey & 0.00 & -1.11 & 1.11 & 1.000 \\
Norway & -0.50 & -1.70 & 0.70 & 0.9513 \\
Czech Republic & -0.10 & -1.30 & 1.10 & 1.000 \\
Portugal & 0.50 & -0.70 & 1.70 & 0.9513 \\
Denmark & 0.50 & -0.70 & 1.70 & 0.9513 \\
\hline
\end{tabular}


Listed in the order of replies, no pairwise comparisons of the post hoc test revealed significant $\mathrm{p}$-value results. This may be an effect that can be observed by greatly varying group sizes and the sheer number of groups ("How to Interpret", 2017). The more groups are compared in a one-way ANOVA, the higher is the likelihood that the overall $\mathrm{p}$-value may indicate significance, while a Tukey HSD post hoc test cannot detect a pairwise significance ("How to Interpret", 2017).

Post hoc analysis for question 29 is presented in table 4. As in the tables before, significant results are highlighted in green.

Table 4

Tukey HSD post hoc test results for question 29. (ANOVA p-value 0.0025)

\begin{tabular}{lcccc}
\hline $\begin{array}{l}\text { Norway } \\
\text { subtracted from }\end{array}$ & Difference & Lower & Upper & p-value \\
\hline Germany & -1.83 & -3.11 & -0.55 & 0.0004 \\
United States & -1.61 & -2.91 & -0.31 & 0.0041 \\
Italy & -1.95 & -3.37 & -0.52 & 0.0009 \\
Netherlands & -1.28 & -2.78 & 0.23 & 0.1763 \\
Belgium & -1.65 & -3.15 & -0.15 & 0.0194 \\
Spain & -1.54 & -3.09 & 0.00 & 0.0506 \\
Turkey & -2.23 & -3.83 & -0.64 & 0.0006 \\
Czech Republic & -1.40 & -3.07 & 0.27 & 0.1877 \\
Portugal & -1.60 & -3.27 & 0.07 & 0.0723 \\
Denmark & -1.80 & -3.47 & -0.13 & 0.0234 \\
\hline
\end{tabular}

This time, Norway appeared to be creating differences in the initial view. Having the Tukey HSD test then aligned for Norway shows discrepancies with most of the other countries. The question about communication necessity, "To resolve conflicts, crew members should openly discuss their differences with each other", is answered with an average value of 3.4 , equaling undecided to disagreeing tendencies, by the Norwegian community, while all other countries either agree or even strongly agree to this statement.

The primary null-hypothesis was that there is no statistically significant difference in the attitude of NATO E-3A aircrew-members toward CRM, based on their nationality. Based on the above gathered results, this can be rejected as certain discrepancies could be detected for different questions. The proposed primary alternate hypothesis can therefore be accepted.

While the primary research question was looking to see if nationalities have influence on crew-members' attitude toward CRM and potentially link unalike attitudes to certain cultural index pattern, the data gathered through the survey questionnaire also allowed to investigate whether secondary factors such 
as gender, crew position, age, time within the NATO E-3A Component, and formal school education affect this attitude. Table 5 shows all those factors and the outcomes for one- way ANOVAs performed on the results for questions 4, 22 , 23,27 , and 29. The two areas that triggered significant $p$-values were the results of question 4 for age groups, p-value being just below 0.05 , and the results of question 23 for crew position, p being very significant below 0.05 , and are again highlighted in green.

Table 5

One-way ANOVA summary of questions 4, 22, 23, 27, 29 by secondary factors.

\begin{tabular}{|c|c|c|c|c|c|c|}
\hline & \multirow{2}{*}{$\mathrm{n}$} & \multicolumn{5}{|c|}{ Mean } \\
\hline & & Q-4 & Q-22 & Q-23 & Q-27 & Q-29 \\
\hline Male & 117 & 2.07 & 2.63 & 1.91 & 4.46 & 1.79 \\
\hline Female & 10 & 1.90 & 2.50 & 1.60 & 4.40 & 1.90 \\
\hline $\begin{array}{l}\text { p-value } \\
\text { (ANOVA) }\end{array}$ & & 0.5574 & 0.6959 & 0.2278 & 0.8328 & 0.7295 \\
\hline Flight crew & 41 & 2.00 & 2.46 & 1.59 & 4.54 & 1.73 \\
\hline Mission crew & 86 & 2.08 & 2.70 & 2.03 & 4.42 & 1.84 \\
\hline $\begin{array}{l}\text { p-value } \\
\text { (ANOVA) }\end{array}$ & & 0.6226 & 0.2290 & 0.0024 & 0.4820 & 0.5467 \\
\hline Time in E-3 < 2 & 40 & 2.03 & 2.38 & 1.95 & 4.30 & 1.85 \\
\hline 2 to 4 years & 47 & 2.09 & 2.87 & 1.94 & 4.47 & 1.89 \\
\hline 5 to 7 years & 14 & 1.79 & 2.43 & 1.71 & 4.43 & 2.00 \\
\hline $\begin{array}{l}8 \text { years and } \\
\text { longer }\end{array}$ & 26 & 2.19 & 2.65 & 1.81 & 4.69 & 1.46 \\
\hline $\begin{array}{l}\text { p-value } \\
\text { (ANOVA) }\end{array}$ & & 0.5549 & 0.1278 & 0.7174 & 0.3716 & 0.1865 \\
\hline Age $<20$ years & 0 & NIL & NIL & NIL & NIL & NIL \\
\hline 20 to 24 years & 1 & 3.00 & 2.00 & 2.00 & 5.00 & 2.00 \\
\hline 25 to 29 years & 5 & 2.40 & 2.40 & 2.00 & 5.00 & 2.40 \\
\hline 30 to 34 years & 20 & 2.50 & 2.90 & 1.90 & 4.40 & 2.00 \\
\hline 35 to 39 years & 32 & 1.88 & 2.84 & 1.91 & 4.44 & 1.53 \\
\hline 40 to 49 years & 47 & 2.06 & 2.40 & 1.96 & 4.38 & 1.81 \\
\hline 50 to 59 years & 22 & 1.77 & 2.59 & 1.68 & 4.55 & 1.86 \\
\hline $\begin{array}{l}60 \text { years and } \\
\text { over }\end{array}$ & 0 & NIL & NIL & NIL & NIL & NIL \\
\hline $\begin{array}{l}\text { p-value } \\
\text { (ANOVA) }\end{array}$ & & 0.0482 & 0.3385 & 0.8536 & 0.7165 & 0.3096 \\
\hline
\end{tabular}




\begin{tabular}{lcccccc}
\hline School edu. $<$ & 4 & 1.75 & 2.75 & 1.25 & 4.75 & 1.75 \\
10 years & 1 & 4.00 & 1.00 & 3.00 & 4.00 & 1.00 \\
11 years & 14 & 2.36 & 3.14 & 2.29 & 4.14 & 1.79 \\
12 years & 11 & 1.64 & 2.64 & 1.82 & 4.27 & 1.73 \\
13 years & 10 & 2.10 & 2.20 & 1.90 & 4.40 & 1.90 \\
14 years & 20 & 2.05 & 2.75 & 1.85 & 4.70 & 1.75 \\
15 years & 17 & 2.29 & 2.53 & 2.06 & 4.47 & 2.05 \\
16 years & 10 & 2.20 & 2.60 & 1.80 & 4.70 & 1.70 \\
17 years & 1.90 & 2.56 & 1.77 & 4.41 & 1.72 \\
$\begin{array}{l}18 \text { years and } \\
\text { more }\end{array}$ & 39 & 1.90 & 0.3961 & 0.2636 & 0.7257 & 0.9461 \\
p-value & & 0.1212 & 0.3961 \\
(ANOVA) & & &
\end{tabular}

Performing a Tukey HSD on question 4, results are shown in Table 6, revealed again no significant variations between two specific age groups. As the crew positions were only distinguished between two groups, no further post hoc test was required for the results of question 23 .

Table 6

Tukey HSD post hoc test results for question 4 for age groups. (ANOVA p-value 0.0482)

\begin{tabular}{lcccc}
\hline $\begin{array}{l}30 \text { to } 34 \text { years } \\
\text { subtracted from }\end{array}$ & Difference & Lower & Upper & p-value \\
\hline 20 to 24 years & 0.5 & -2.01 & 3.01 & 0.9923 \\
25 to 29 years & -0.1 & -1.32 & 1.12 & 0.9999 \\
35 to 39 years & -0.63 & -1.32 & 0.07 & 0.1063 \\
40 to 49 years & -0.44 & -1.09 & 0.22 & 0.3869 \\
50 to 59 years & -0.73 & -1.48 & 0.03 & 0.0666 \\
\hline
\end{tabular}

The secondary research question asked whether other personal factors such as gender, crew position, time spent in the NATO E-3A Component, age, or school education of NATO E-3A aircrew-members influence his or her attitude toward CRM. The null hypotheses H02, H04, and H06; no differences based on gender, time spent in the NATO E-3A component, and school education; can be retained based on the results obtained from the statistical analysis. 


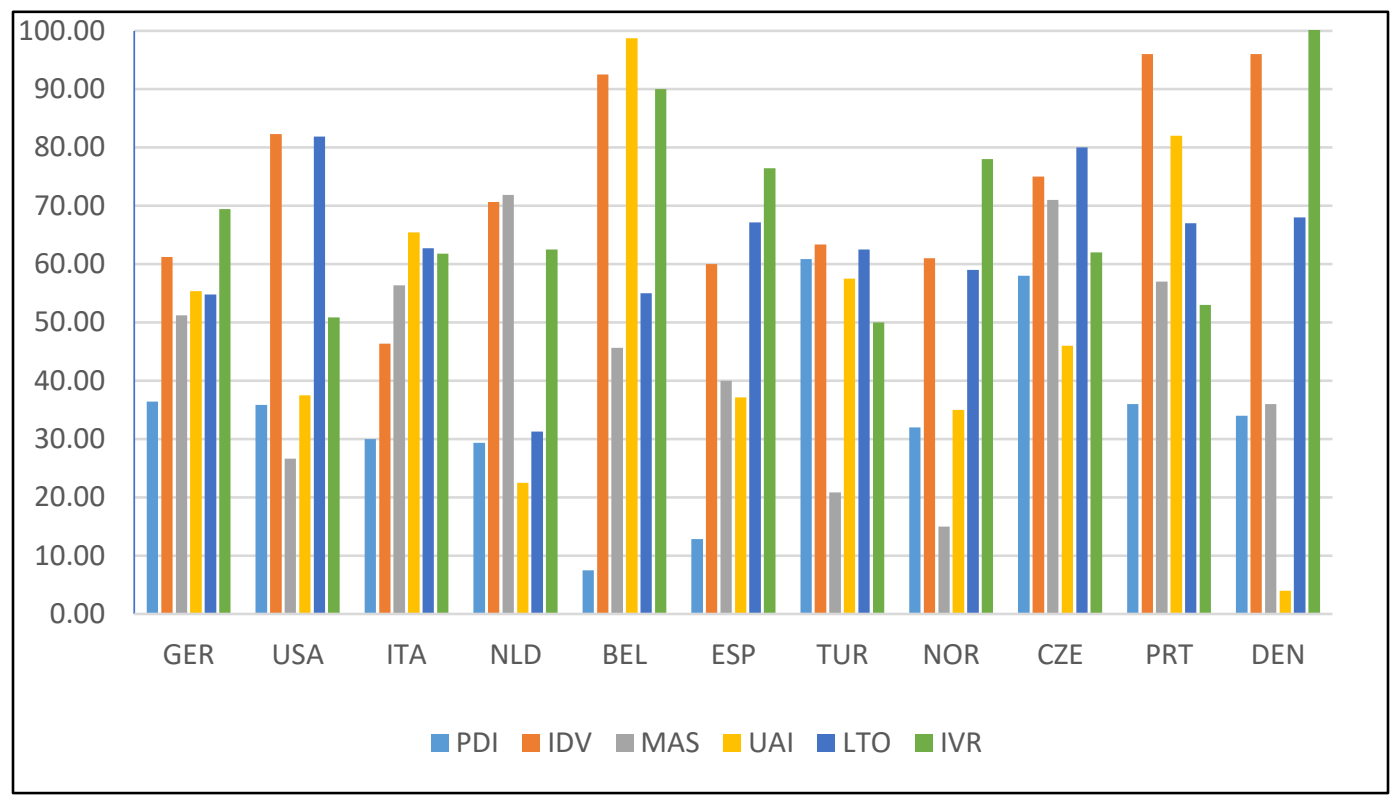

As the analyses of crew position and age has resulted in only one survey question creating discrepancies each, the answer to this question is rather difficult. Due to the fact that the Tukey post hoc test of question 4 for age groups could not reveal two certain groups that against each other create a $p$-value of $p \leq 0.05$, it is more likely that $\mathrm{H} 03$ has to be retained as well.

The differences between flight crew and mission crew for question 23 is more pronounced with a p-value of 0.0024 , which leads to a rejection of H05 and the acceptance of the alternate hypothesis that differences in the attitude of NATO E-3A crew member toward CRM, based on the crew position actually exist.

Besides, to detect if an overall discrepancy on attitudes toward CRM exists, the study also wanted to investigate whether such differences could be linked to certain pattern of cultural indices as they are described by Hofstede (2001). Figure 3 illustrates the six cultural indices calculated from the actual data of the survey. Being vastly different for all countries, as the original data from Hofstede's initial survey decades ago, Figure 4 provides an analysis and ranking of the different indices and countries. The colors in the analysis table change from red to green from low to high and the blue bars inside the boxes show a graphical translation of the specific index that are equal to the one in Figure 3. 


\begin{tabular}{|c|c|c|c|c|c|c|}
\cline { 2 - 7 } \multicolumn{1}{c|}{} & PDI & IDV & MAS & UAI & LTO & IVR \\
\hline ESP & 12,86 & 60,00 & 40,00 & 37,14 & 67,14 & 76,43 \\
ITA & 30,00 & 46,36 & 56,36 & 65,45 & 62,73 & 61,82 \\
\hline NOR & 32,00 & 61,00 & 15,00 & 35,00 & 59,00 & 78,00 \\
\hline GER & 36,43 & 61,25 & 51,25 & 55,36 & 54,82 & 69,46 \\
USA & 35,83 & 82,29 & 26,67 & 37,50 & 81,88 & 50,83 \\
NLD & 29,38 & 70,63 & 71,88 & 22,50 & 31,25 & 62,50 \\
\hline BEL & 7,50 & 92,50 & 45,63 & 98,75 & 55,00 & 90,00 \\
\hline TUR & 60,83 & 63,33 & 20,83 & 57,50 & 62,50 & 50,00 \\
CZE & 58,00 & 75,00 & 71,00 & 46,00 & 80,00 & 62,00 \\
\hline PRT & 36,00 & 96,00 & 57,00 & 82,00 & 67,00 & 53,00 \\
\hline DEN & 34,00 & 96,00 & 36,00 & 4,00 & 68,00 & 137,00 \\
\hline
\end{tabular}

Figure 4. Cultural indices determined in this study - Analysis.

Having a closer look now at the three countries that created dissimilarities in the previous calculations; Spain, Italy, and Norway; listed as the first three in the table, shows that they are only in very few areas within an extreme range of the scale. To be exact, Spain appears at the lower end of the scale for Power Distance, while Norway is the lowest of the group in the Masculinity dimension. Other than that, there is no real pattern that could be observed throughout the three countries in question but they are more or less within the central range within each index.

\section{Conclusion}

This study was based on the idea to correlate cultural dimensions and attitude toward CRM. While correlation is not causation and Hofstede and Minkov (2013) have warned to use the originally published scores as a source for comparison, the purpose of this study was to find out, whether such a link between national cultures and attitude exists.

To gauge the attitude toward CRM based on only five questions might have had its limits. Nonetheless, it seemed to be the most probable means to assess attitude without 1) negatively influencing the purpose of the research to the participants and 2) following the ethical principles of research with human subjects.

In this project, significant statistical differences could be detected in three of the five questions, indicating that national culture and the attitude toward CRM does correlate and hence needs to be addressed in CRM training. 
It was not the intent of this study to point the finger on a particular nation. Rather, the exact opposite was supposed to be achieved. CRM is not perfect and is, as always reiterated, a constantly evolving construct. One part of it, in the now globalized and more and more interrelated world, is to deal with different baselines that each culture brings into this coherent model. But CRM once was created with a mental model that could have only been based on a western culture, as CRM historically was essentially a U.S. achievement.

To find out how to adjust CRM and how to make it a universal model workable in the same effective manner for all different cultures and nationalities, is the great challenge that lies within the future of globalization in aviation when relying on CRM further. Hence, the actual study can only serve as a starting point. The findings suggest only scientifically what would already been expected: Differences between different nations do actually exist. Despite the existence of these differences, cultural dimension indices, as they were introduced by Hofstede (2011) earlier, seem not to be the right tool to read out these differences.

Future studies should increase the scope of similar research ideas. Henceforth, the number of various participating nations to also include groups from Asia, South America, and Africa. If CRM will remain an integral part of the future aviation team concept, it has to adapt to be either useable for all nationalities and cultural backgrounds, or it has to come up with various versions that are usable for defined parts of the world. 


\section{References}

Aebersold, M., Tschannen, D., \& Sculli, G. (2013). Improving nursing students' communication skills using crew resource management strategies. Journal of Nursing Education, 53(3), 125-130.

Aktas, E., \& Tekarslan, E. (2013). Crew resource management: The relationships between personality types and crew resource management attitudes of pilots. Istanbul University Journal of the School of Business, 42(2), 276-301.

Besco, R. O. (1997). The need for operational validation of human relationscentered CRM training assumptions: A critical review of curriculum content and training methodology assumptions in crew resource management training. In R. S. Jensen \& L. Rakovan (Eds.), Proceedings of the 10th International Symposium on Aviation Psychology, 536-540. Columbus, $\mathrm{OH}$ : Ohio State University.

Compare countries. (2018). Retrieved September 29, 2018 from https://www.hofstede-insights.com/product/compare-countries/

E-3A component. (2018). Retrieved from https://www.e3a.nato.int/ page5835237.aspx

Eringa, K., Caudron, L. N., Rieck, K., Xie, F., \& Gerhart, T. (2015) How relevant are Hofstede's dimensions for inter-cultural studies? A replication of Hofstede's research among current international business students. Research in Hospitality Management, 5(2), 187-198.

Gordon, S., Mendenhall, P., \& O'Connor, B. B. (2012). Beyond the checklist. New York, NY: ILR Press.

Helmreich, R. L., Merritt, A. C., \& Wilhelm, J. A. (1999). The evolution of crew resource management training in commercial aviation. The International Journal of Aviation Psychology, 9(1), 19-32.

Helmreich, R. L., Wilhelm, J. A., Klinect, J. R., \& Merritt, A. C. (2001). Culture, error, and crew resource management. In E. Salas, C. A. Bowers \& E. Edens (Eds.), Applying resource management in organizations: A guide for professionals. Hillsdale, NJ: Erlbaum.

Helmreich, R. L., \& Merritt, A. C. (2016). Culture at work in aviation and medicine - National, organizational and professional influences. New York, NY: Routledge.

Hofstede, G. (2001). Culture's consequences: Comparing values, behaviors, institutions, and organizations across nations. Thousand Oaks, CA: SAGE Publications.

Hofstede, G., \& Minkov, M. (2013). Values survey module 2013. Retrieved February 15, 2018 from http://geerthofstede.com/research-and-vsm/vsm2013/ 
How to interpret contradictory results between ANOVA and multiple pairwise comparisons. (2017). Retrieved from https://help.xlstat.com/customer/ es/portal/articles/2852820-how-to-interpret-contradictory-results-betweenanova-and-multiple-pairwise-comparisons-?b_id=9283

Kanki, B., Helmreich, R., \& Anca, J. (2010). Crew resource management. Cambridge, MA: Academic Press.

Keppel, G., \& Wickens, T. D. (2004). Design and analysis: A researcher's handbook (4th ed.). New York, NY: Pearson Education.

Komich, J. (1997). CRM training: Which crossroads to take now? In R. S. Jensen \& L. A. Rakovan (Eds.), Proceedings of the 9th International Symposium on Aviation Psychology, 541-546. Columbus: Ohio State University.

Merritt, A. C., \& Helmreich, R. L. (1996). Human factors on the flight deck - The influence of national culture. Journal of Cross-Cultural Psychology, 27(1), 524.

Mücklich, N. G. (2017). Measuring attitudes toward ramp resource management: The influence of national culture (Unpublished master's thesis). EmbryRiddle Aeronautical University, Worldwide Campus.

National Transportation Safety Board. (1979). Aircraft accident report. Retrieved March 2, 2017 from http://libraryonline.erau.edu/online-fulltext/ntsb/aircraft-accident-reports/AAR79-07.pdf

National Transportation Safety Board. (2010). Aircraft accident report. Retrieved March 3, 2017 from https:/www.ntsb.gov/investigations/ AccidentReports/ Reports/AAR1003.pdf

North Atlantic Treaty Organization. (2015). Strategic airlift capability (SAC). Retrieved from https://www.nato.int/cps/en/natohq/topics_50105.htm

Participating Nations. (2018). Headquarters early warning and control force. Retrieved from https://www.e3a.nato.int/organisation/participatingnations.aspx

Reid, D. (2017, June 20). Airline industry facing a massive shortfall of pilots, survey says. CNBC. Retrieved from https://www.cnbc.com/2017/06/20/thisis-your-captain-retiring--world-faces-pilot-shortage.html

Salas, E., Bowers, C. A., \& Edens, E. (2001). Improving teamwork in organizations: applications of resource management training. Mahwah, NJ: Lawrence Erlbaum Associates.

Salas, E., Wilson, K. A., Burke, C. S., \& Wightman, D. C. (2006). Does crew resource management training work? An update, an extension, and some critical needs. Human Factors, 48(2), 392-412.

Schulz von Thun, F. (2001). Miteinander reden [Talking to each other] (49th ed.). Hamburg: Rohwolt. 
Simmon, D. A. (1997). How to fix CRM. In R. S. Jensen \& L. A. Rakovan (Eds.), Proceedings of the 9th International Symposium on Aviation Psychology, 550-553. Columbus: Ohio State University.

Verbeek-van Noord, I., de Bruijne, M. C., Twisk, J. W. R., van Dyck, C., \& Wagner, C. (2014). More explicit communication after classroom-based Crew Resource Management training: Results of a pragmatic trial. Journal of Evaluation in Clinical Practice, 21, 137-144.

Weiss, N., A. (2011). Introductory statistics (9th ed.). New York, NY: Pearson Education. 


\section{List of Acronyms}

$\begin{array}{ll}\text { ANOVA } & \text { Analysis of Variance } \\ \text { AWACS } & \text { Airborne Early Warning and Control System } \\ \text { CRC } & \text { Control and Reporting Center } \\ \text { CRM } & \text { Crew Resource Management } \\ \text { FMAQ } & \text { Flight Management Attitudes Questionnaire } \\ \text { HSD } & \text { Honest Significance Difference } \\ \text { IDV } & \text { Individualism Index } \\ \text { IVR } & \text { Indulgence versus Restraint Index } \\ \text { LTO } & \text { Long-Term Orientation Index } \\ \text { MAS } & \text { Masculinity Index } \\ \text { NATO } & \text { North Atlantic Treaty Organization } \\ \text { NTSB } & \text { National Transportation Safety Board } \\ \text { PDI } & \text { Power Distance Index } \\ \text { RRM } & \text { Ramp Resource Management } \\ \text { TEM } & \text { Threat and Error Management } \\ \text { UAI } & \text { Uncertainty Avoidance Index } \\ \text { VSM } & \text { Values Survey Module }\end{array}$

